\section{Neologismos por empréstimo no domínio discursivo da moda: do registro jornalístico ao lexicográfico}

Foreignness and loanwords in fashion texts: from journalistic to lexicographic registry

Camille Roberta Ivantes BRAZ (UERJ) crib14@gmail.com

Flávio de Aguiar BARBOSA (UERJ) flavioab.uerj@gmail.com

Recebido em: 26 de jul. de 2020. Aceito em: 24 de ago. de 2020.
BRAZ, Camille Roberta Ivantes; BARBOSA, Flávio de Aguiar.

Neologismos por empréstimo no domínio discursivo da moda: do registro jornalístico ao lexicográfico. Entrepalavras, Fortaleza, v. 11, n. esp., p. 81-102, ago. 2021. DOI: 10.22168/2237-6321-10esp2013.

Resumo: Esta pesquisa realizou um estudo lexicológico e metalexicográfico de termos estrangeiros do domínio discursivo da moda, recolhidos no semanário ELA do jornal $O$ Globo, no período de 2000 a 2015. Escolheuse a moda como domínio discursivo, principalmente, porque uma característica importante nos textos de moda é a adoção de palavras estrangeiras e havia interesse dos pesquisadores em observar os usos desse tipo de palavra no vocabulário em pauta. Os termos selecionados nos textos foram analisados e comparados com seus verbetes nos dicionários que compõem o corpus lexicográfico, além do Vocabulário Ortográfico da Língua Portuguesa, o VOLP (tanto em sua versão impressa quanto em sua versão on-line). O objetivo principal foi o de obter uma ideia mais precisa a respeito da incorporação das palavras do corpus ao léxico da língua portuguesa, levando-se em conta a dicionarização como principal elemento de referência. Analisou-se o percurso da utilização das palavras estrangeiras dos textos jornalísticos até a formalização pelos dicionários da língua portuguesa. Procurou-se verificar como, na sociedade contemporânea, as mudanças linguísticas se 'impõem' aos dicionários, em razão da rapidez com a qual os meios de comunicação adotam as palavras de outros idiomas.

Palavras-chave:

Empréstimos. Lexicografia.

Estrangeirismos. 
v. 11 (esp.)

81-102 ago. 2021

Abstract: This research does a lexicological and a metalexicographic study of foreign terms from the discoursive domain of fashion, collected in the weekly ELA from the newspaper O Globo from 2000 to 2015. Fashion was chosen as the subject mainly because it is an important characteristic in fashion texts the adoption of foreign words. The words selected in the texts were analyzed and compared with their entries in the dictionaries from the lexicographic corpus, in addition of the Vocabulário Ortográfico da Língua Portuguesa, the VOLP (both in its printed version and in its online version). The main objective was to have an more precise idea regarding the incorporation of the words of the corpus into the lexicon of the Portuguese language, taking into account the dictionary as the main reference. The path from the use of foreign words in journalistic texts to the formalization by the Portuguese languages dictionaries was analyzed. We tried to verify how, in contemporary society, linguistic changes are « imposed » on dictionaries because of the speed with which the media adopt the words from other languages.

Keywords: Foreignness. Loanwords. Lexicography.

\section{Introdução}

A adoção de palavras estrangeiras parece ser um fenômeno contemporâneo, fruto de um mundo tecnológico que aparenta não ter mais fronteiras ou grandes distâncias separando as nações e seus habitantes. A incorporação de vocábulos provenientes de outras línguas, contudo, é algo inevitável, desde que a humanidade começou a experimentar os intercâmbios comerciais e culturais.

Todo idioma em uso é flexível e se modifica constantemente, a fim de atender às necessidades comunicativas de seus falantes. São essas necessidades comunicativas que provocam mudanças e envolvem a criação de novas palavras. Alves (2007, p. 5, grifos da autora) explica que

ao processo de criação lexical dá-se o nome de neologia. O elemento resultante, a nova palavra, é denominado neologismo. O neologismo pode ser formado por mecanismos oriundos da própria língua, os processos autóctones, ou por itens léxicos provenientes de outros sistemas linguísticos.

O presente artigo tratou do último caso, a fim de entender melhor como tais palavras, pertencentes a outros idiomas, foram incorporadas pelos falantes de português (que, muitas vezes, não dominam a língua da qual o vocábulo se origina). A opção deste estudo foi pesquisar neologismos por empréstimo no domínio discursivo ${ }^{1}$ da moda,

\footnotetext{
${ }^{1} \mathrm{O}$ conceito de domínio discursivo adotado é o de Marcuschi (2002, p.23, grifos do autor), que explica que esta expressão é usada "[..] para designar uma esfera ou instância de produção discursiva ou de atividade humana. [...] Constituem práticas discursivas dentro das quais podemos identificar um conjunto de gêneros textuais que, às vezes lhe são próprios (em certos casos exclusivos) como práticas ou rotinas comunicativas institucionalizadas."
} 
escolha que se deveu ao fato de a adoção de termos estrangeiros ser uma das características marcantes dessa área. O objetivo a ser alcançado, a partir da identificação dos itens lexicais nos textos selecionados sobre o tema, foi o de analisar como essas palavras oriundas de outros idiomas são dicionarizadas e, assim, legitimamente incorporadas ao léxico do português.

Para realizar esta parte do estudo, escolheu-se como material de pesquisa um caderno jornalístico, o ELA do jornal O Globo. Desde o final de 2017, o caderno ELA passou a ter o formato de uma revista dominical, mas, à época da pesquisa, se tratava de um caderno jornalístico publicado aos sábados. O semanário, quando pesquisado, apresentava crônicas e matérias jornalísticas que abordavam cultura, arte, beleza, gastronomia, celebridades, mas, sobretudo, moda. Apresentava também reportagens sobre eventos do setor (semanas de moda, exposições históricas sobre o assunto, lançamentos de lojas etc.), entrevistas com profissionais (estilistas, designers de estampas, produtores de matériaprima etc.) e editorias de moda (roupas, sapatos, acessórios etc.). Para este estudo, foram analisados, exclusivamente, textos jornalísticos que tratam de moda - entendem-se como textos jornalísticos sobre o assunto aqueles que abordam produção, criação, comercialização e divulgação de novidades sobre matéria-prima e produtos finalizados de vestuário e acessórios (joias, calçados, bolsas, chapéus etc.), história da moda nacional e internacional, entrevistas com profissionais do setor, educação e pesquisa sobre moda, além de eventos nacionais e internacionais da área.

O propósito deste artigo foi analisar o percurso do vocabulário da moda, adotando-se, como ponto de partida, o uso em textos jornalísticos e, como ponto de chegada, a formalização pela inserção em dicionários gerais da língua. Observou-se, portanto, se os neologismos por empréstimo identificados na pesquisa já integram os dicionários impressos publicados mais recentemente no Brasil e os dicionários virtuais de consulta gratuita na internet pesquisados.

A relevância deste estudo está na verificação de como, na sociedade contemporânea, as mudanças linguísticas se "impõem" aos dicionários tradicionais, em razão da rapidez com que os meios de comunicação incorporam os empréstimos. Por isso, buscou-se também refletir a respeito das diferenças entre as obras lexicográficas impressas e os dicionários on-line abertos à contribuição de usuários que não são, necessariamente, lexicógrafos. 
v. 11 (esp.)

81-102 ago.

2021

\section{Embasamento teórico}

As criações e mudanças lexicais não acontecem aleatoriamente (os mecanismos para criação de palavras estão previstos no sistema gramatical). Azeredo (2012, p. 399, grifos do autor) explica que "ao conjunto dos processos de renovação lexical de uma língua se dá o nome de neologia, e às formas e acepções criadas ou absorvidas pelo seu léxico, neologismos."

Neste estudo, também se dedica atenção à renovação e ampliação do léxico por incorporação de palavras estrangeiras, compreendendo esse recurso nos termos de Biderman (1978, p. 162), para quem os empréstimos estrangeiros são "outro tipo de neologismo formal e conceptual [...]. Nessa categoria se incluem lexemas das mais variadas procedências linguísticas: anglicismos, galicismos, latinismos, italianismos, arabismos, niponismos, etc.".

No caso específico do português (que, assim como as demais línguas românicas, tem como base o latim vulgar), houve, já em épocas remotas, a adoção de palavras de línguas germânicas e árabes, além de termos em castelhano, francês, inglês, italiano... A língua portuguesa falada no Brasil, por sua vez, é o que Basso e Gonçalves (2014, p. 189) chamam de "uma variedade de português" formada por influências dos africanos que para cá vieram com línguas de diversas procedências; dos índios, sobretudo os tupis, cuja língua chegou a se tornar a língua geral do Brasil, sendo ensinada na escola; e também de muitos portugueses, provenientes de diferentes regiões lusitanas, que vieram colonizar o novo território.

Mais tarde, os processos de imigração trouxeram (e ainda trazem), para o Brasil, indivíduos dos mais diversos países, e o processo de absorção e adaptação de termos estrangeiros se torna ininterrupto. Portanto, seja na formação do português europeu seja na formação do português brasileiro, existem palavras que provêm de vários idiomas, e muitas são usadas até hoje sem que se pense muito a respeito de sua origem.

O fato é que a incorporação de termos estrangeiros é fenômeno incontrolável e inevitável por ser fruto de processos históricos e socioculturais. No caso específico do domínio discursivo da moda, na virada do século XIX para o XX, os termos franceses eram muito adotados, isto porque a França (sobretudo sua capital, Paris) era a referência mundial de elegância, luxo e bem-vestir. E mesmo que até 
hoje o país europeu continue a ocupar uma posição de destaque quando se pensa no assunto, vê-se uma adoção cada vez maior de anglicismos neste domínio discursivo específico. Tal alternância nada mais é que o reflexo da mudança do eixo cultural de maior prestígio no mundo - se antes era francês, atualmente é estadunidense. Assim, pode-se afirmar que a adoção de um estrangeirismo dependerá da necessidade real proveniente de uma lacuna lexical ou da necessidade de identificação com a cultura de maior prestígio.

É preciso também ressaltar que, enquanto algumas palavras estrangeiras são adotadas e permanecem com grafia inalterada (sendo assim, dicionarizadas e legitimadas), outras são aportuguesadas. Desta forma, é útil que se faça a diferenciação entres os termos estrangeirismo e empréstimo. Correia e Almeida (2012, p. 71) fornecem a seguinte explicação para os dois,

[...] "estrangeirismo" denota uma unidade importada de outra língua que não sofreu quaisquer adaptações à língua de chegada, ao passo que "empréstimo" denota uma palavra estrangeira que se adaptou ao sistema linguístico de acolhimento, ou seja, no nosso caso, que foi aportuguesada.

Neste trabalho, essas foram as conceituações adotadas para a exposição e a análise de dados.

\section{Metodologia de pesquisa}

De acordo com Oliveira (2013, p. 18), os indícios do surgimento da moda datam do Renascimento "[...] em que se revela uma nova classe social, a burguesia [...]". O que antes era restrito aos nobres, em termos de vestuário, passou a ser "acessível" aos burgueses, à medida que sua classe social crescia em poder econômico. No século XVIII, quando acontece a disputa de poder político entre nobreza e burguesia, as roupas tornam-se símbolos de status social e é neste período que surgem as primeiras revistas femininas. Passou a ser papel da imprensa especializada a divulgação das tendências e de seus estilistas criadores que alguns seguem por opção e outros por imposição (porque o que é produzido para ser comercializado em grande escala, de alguma forma, sempre se espelha no que acontece nas passarelas de moda).

O que se observou nesta análise dos textos do Caderno ELA foi que os estrangeirismos, em maioria, não apareceram destacados e/ou traduzidos, e muitos jargões do setor sequer são explicados. De acordo 


\section{v. 11 (esp.)}

81-102 ago. 2021

com Charaudeau (2008, p. 44), "[...] o ato de linguagem como evento de produção ou de interpretação, depende dos 'saberes supostos que circulam entre os protagonistas da linguagem'", ou seja, se o leitor não dispuser dos mesmos saberes expostos pelo falante (no caso dos textos do ELA, o jornalista), a comunicação não é bem-sucedida. A escolha lexical, dessa forma, foi deliberada e, ao se considerar tudo isso, tornouse possível levantar a hipótese de que a falta de necessidade de distinguir palavras vernáculas de estrangeiras nos textos do ELA reside no fato de que, para o destinatário (ou seja, o leitor), elas não são diferentes dos termos vernáculos no sentido da compreensão do significado. Uma outra possibilidade pode ser simplesmente que há receptividade a essas palavras pelo valor de sofisticação que elas conferem ao texto.

Ao se entender que as palavras são "eleitas" pelos falantes (de acordo com suas necessidades), constatou-se que lhe cabe adotar os termos que melhor atendem a suas necessidades (tanto referenciais quanto valorativas) e, assim, construir uma fala que passa a utilizar palavras estrangeiras desse domínio discursivo para tratar do assunto. Em alguns casos, os termos tornam-se tão difundidos e necessários para o processo comunicativo que acabam por se integrar ao léxico comum; uma das formas de se diagnosticar a legitimação desse vocabulário na língua é valer-se dos registros lexicográficos.

A opção desta pesquisa por textos jornalísticos foi justificada pela afirmativa de Carvalho (1987, p. 61): "[...] a maneira mais fácil de tomar conhecimento de uma inovação linguística é através da imprensa".

O caderno ELA do jornal O Globo teve 829 exemplares analisados $^{2}$, todos publicados entre 2000 e 2015. Os textos de moda escolhidos (de acordo com os parâmetros apresentados na introdução deste artigo) foram todos digitados no formato *txt e processados por meio do programa de computador Wordsmith Tools.

O Wordsmith Tools é um programa que existe desde 1996 e é feito pela Oxford University Press. Ele é capaz de gerar listas de palavras por frequência e em ordem alfabética, listas de palavras em contexto (que foram funções bastante usadas nesta pesquisa), além de outros recursos de análise lexical. De acordo com informações do próprio website $^{3}$ no qual pode ser adquirido, o programa trata-se de um

\footnotetext{
${ }^{2}$ Três exemplares do mês de maio do ano 2000 não puderam ser analisados - 06/05, 13/05 e 20/05 - por problemas de visibilidade dos textos nos arquivos digitais disponíveis no acervo do jornal O Globo.
}

${ }^{3}$ Disponível em: http://lexically.net/LexicalAnalysisSoftware/. Acesso em 10/06/2017. 
software usado para encontrar padrões no texto. Usado mundialmente por estudantes de língua, professores, pesquisadores e investigadores trabalhando em campos como linguística, literatura, direito, medicina, história, política, sociologia. Contempla a maioria das línguas incluindo chinês, japonês, etc. (tradução nossa4)

Com o auxílio do programa, puderam-se identificar os dez empréstimos linguísticos e os dez estrangeirismos mais recorrentes nos textos do ELA. Esses vinte itens lexicais foram pesquisados em dicionários gerais de língua portuguesa e no Vocabulário Ortográfico da Língua Portuguesa (doravante, VOLP) da Academia Brasileira de Letras, tanto a versão impressa mais recente quanto a disponível no site oficial da Academia Brasileira de Letras 5 .

A seleção dos itens lexicais de ambos os grupos obedeceu ao seguinte critério: a lexia deveria constar em todos os anos das edições do Caderno ELA pesquisadas (2000-2015) e deveria ter uma alta frequência no corpus (pertencer ao grupo dos dez empréstimos/estrangeirismos mais recorrentes no semanário). Assim, a partir dos dados fornecidos pelo Wordsmith Tools, chegou-se a duas listas, contendo dez palavras cada:

Grupo A - Empréstimos: 1) Moda: 5.386 ocorrências; 2) Grife: 2.288 ocorrências; 3) Modelo: 1.839 ocorrências; 4) Estampa: 1.234 ocorrências; 5) Joia: 1.034 ocorrências; 6) Passarela: 827 ocorrências; 7) Ateliê: 470 ocorrências; 8) Chique: 331 ocorrências; 9) Tricô: 301 ocorrências e 10) Tênis: 285 ocorrências.

Grupo B - Estrangeirismos: 1) Fashion: 2.034 ocorrências; 2) Designer: 1.183 ocorrências; 3) Look: 713 ocorrências; 4) Jeans: 672 ocorrências; 5) Top: 428 ocorrências; 6) Maison: 195 ocorrências; 7) Short: 191 ocorrências; 8) Hype $e^{6} 162$ ocorrências; 9) Vintage: 162 ocorrências e 10) Lingerie: 138 ocorrências.

\footnotetext{
${ }_{4}^{4}$ No original: "software for finding patterns in text. Used world-wide by language students, teachers, researchers and investigators working in such fields as linguistics, literature, law, medicine, history, politics, sociology. Can handle most languages including Chinese, Japanese, etc.".

5 VOLP: (http://www.academia.org.br/nossa-lingua/busca-no-vocabulario).

${ }^{6}$ Como hype e vintage atingiram o mesmo número de ocorrências, optou-se por colocar hype como a de número 8, seguindo o critério de ordem alfabética.
} 
v. 11 (esp.)

81-102 ago. 2021

Em seguida, constituiu-se um corpus lexicográfico de 21 dicionários, dentre os quais 19 são gerais da língua (16 impressos e três on-line de acesso gratuito). O corpus lexicográfico se completa com um dicionário etimológico - Dicionário Etimológico da língua portuguesa, de Antônio Geraldo da Cunha - e um de usos, o Dicionário UNESP do português contemporâneo. O Dicionário Houaiss da língua portuguesa, edição de 2001, tem dupla função: é usado como dicionário geral e etimológico7.

O critério de escolha dos dicionários foi norteado pelos objetivos a serem alcançados para o prosseguimento da pesquisa. Assim, buscouse constituir um corpus lexicográfico que proporcionasse:

- rastreamento cronológico das lexias, tanto dos registros mais antigos em dicionários quanto de desdobramentos semânticos;

- identificação de definições atualizadas, com a finalidade de constatar até que ponto os dicionários modernos (tanto impressos quanto virtuais) contemplam a renovação lexical que se identifica no corpus;

- referência etimológica, para identificar a origem das lexias estudadas.

O corpus lexicográfico organizou-se da seguinte forma:

\section{1) Dicionários Gerais da Língua Portuguesa:}

Impressos:

Século XVIII: 1712-1728 - Vocabulario portuguez \& latino: aulico, anatomico, architectonico ... de Raphael Bluteau (doravante, Bluteau); 1789 - Diccionario da lingua portugueza - recompilado dos vocabularios impressos ate agora, e, nesta segunda edição, novamente emendado e muito acrescentado, de Antonio Moraes Silva (doravante, Moraes Silva);

Século XIX: 1881 - Diccionario contemporaneo da lingua portuguesa, de Francisco Júlio de Caldas Aulete (doravante, Aulete 1881);

Século XX: 1957 - Grande e novíssimo dicionário da língua portuguesa, de Laudelino Freire (doravante, Laudelino Freire);

\footnotetext{
7 Não foram consultadas outras obras disponíveis on-line, como os dicionários Priberam da Língua Portuguesa (https://www.priberam.pt/DLPO/) e o Dicionário de Língua Portuguesa da Porto Editora (http://www.infopedia.pt/dicionarios/lingua-portuguesa/), por serem dedicados ao português europeu.
} 
1958 - Dicionário contemporâneo da língua portuguesa Caldas Aulete (doravante, Aulete 1958);1964 - Dicionário contemporâneo da língua portuguesa Caldas Aulete (doravante, Aulete 1964); 1974 - Dicionário contemporâneo da língua portuguesa Caldas Aulete (doravante, Aulete 1974); 1980 - Dicionário contemporâneo da língua portuguesa Caldas Aulete (doravante, Aulete 1980); 1975 Novo dicionário Aurélio da língua portuguesa (doravante, Aurélio 1975); 1986 - Novo dicionário Aurélio da língua portuguesa (doravante, Aurélio 1986); 1987 - Dicionário contemporâneo da língua portuguesa Caldas Aulete (doravante, Aulete 1987); 1999 Aurélio Século XXI - o dicionário da língua portuguesa (doravante, Aurélio 1999);

Século XXI: 2001 - Dicionário Houaiss da língua portuguesa (doravante, Houaiss 2001); 2004 - Novo dicionário Aurélio da língua portuguesa (doravante, Aurélio 2004); 2009 - Dicionário Houaiss da língua portuguesa (doravante, Houaiss 2009); 2010 Novo dicionário Aurélio da língua portuguesa (doravante, Aurélio 2010); 2011 - Novíssimo Aulete - dicionário contemporâneo da língua portuguesa (doravante, Aulete 2011);

Virtuais:

Aulete digital: http://www.aulete.com.br/ (doravante, Aulete digital); Dicionário inFormal: http://www.dicionarioinformal. com.br/ (doravante, Dicionário InFormal) e Dicio - Dicionário on-line de português: http://www.dicio.com.br/ (doravante, Dicio);

\section{2) Dicionário de usos:}

2004 - Dicionário UNESP do português contemporâneo (doravante, Dicionário UNESP);

\section{3) Dicionário Etimológico da Língua Portuguesa:}

2010 - Dicionário Etimológico da língua portuguesa de Antônio Geraldo da Cunha (doravante, Dicionário AGC). 
v. 11 (esp.)

81-102 ago.

2021

\section{Análise de Dados}

Iniciou-se a exposição pelos dados encontrados no VOLP. A razão para esta escolha residiu na percepção de que essa é uma fonte fundamental de referência para o registro ortográfico, à qual se recorre, muitas vezes, até mesmo antes de uma consulta a dicionários. Como há indicação de que é atualizado periodicamente e de que seu conteúdo está disponível na internet gratuitamente, supõe-se que o VOLP registre unidades presentes nos dicionários de língua portuguesa e vá além, apresentando algumas que ainda não foram inseridas nos dicionários. Isso faz dele uma referência para se decidir se uma palavra ainda é um neologismo ou não.

Do Grupo A o resultado obtido nas edições impressa e on-line ${ }^{8}$ foi rigorosamente o mesmo: estavam presentes todos os dez empréstimos linguísticos desta busca; já do Grupo B, enquanto não há nenhum item na edição impressa, a versão on-line registrou cinco estrangeirismos do corpus: designer, jeans, top, short e lingerie. Sendo assim, de acordo com o VOLP, fashion, maison, hype, look e vintage são neologismos. Porém, este resultado não se confirmou para fashion, look e vintage, que estão legitimadas por dicionários impressos pertencentes ao corpus lexicográfico deste estudo. Maison e hype, porém, foram encontradas em apenas um dicionário virtual feito com a colaboração de usuários o Dicionário InFormal.

No tocante à origem das lexias, o que se identificou na pesquisa foi que, entre os empréstimos linguísticos, a maioria de itens vem do francês (ateliê, chique, grife, joia, moda, passarela e tricô), totalizando sete; seguem-se duas lexias vindas do italiano (estampa e modelo) e apenas uma do inglês (tênis). Entre os estrangeirismos, foram identificados oito anglicismos (designer, fashion, hype, jeans, look, short, top, vintage) e dois francesismos (lingerie e maison). Este resultado, portanto, mostrou que, se, até meados do século XX, tinha-se uma absorção maior de termos provenientes do francês, com a mudança de cultura de prestígio da francesa para a estadunidense, absorveramse mais termos do inglês.

Levando-se em conta a prudência que costuma nortear o processo de incorporação de um neologismo por um dicionário geral da língua, pode-se afirmar que os termos estrangeiros desta busca

8 VOLP: http://www.academia.org.br/nossa-lingua/busca-no-vocabulario. Acesso em: 31/05/2020. 
já estavam em uso pelos falantes muito antes das suas inserções nos primeiros dicionários pesquisados nos quais aparecem. Optou-se por se tomar a data de publicação do primeiro dicionário do corpus lexicográfico no qual foi identificada a palavra como a data de formalização da lexia no português por questões de organização. Maison e hype não aparecem na lista abaixo, porque só foram encontradas em um dicionário virtual.

- Lexia: ESTAMPA - origem: italiano. Data: $1712-1728$. Dicionário: Bluteau;

- Lexia: JOIA - origem: francês. Data: 1712 -1728. Dicionário: Bluteau;

- Lexia: MODA - origem: francês. Data: $1712-1728$. Dicionário: Bluteau;

- Lexia: MODELO - origem: italiano. Data: 1712 -1728. Dicionário: Bluteau;

- Lexia: CHIQUE - origem: francês. Data: 1957. Dicionário: Laudelino Freire;

- Lexia: TRICÔ - origem: francês. Data: 1957. Dicionário: Laudelino Freire;

- Lexia: PASSARELA - origem: francês. Data: 1964. Dicionário: Aulete 1964;

- Lexia: ATELIÊ - origem: francês. Data: 1975. Dicionário: Aurélio 1975;

- Lexia: LINGERIE - origem: francês. Data: 1975. Dicionário: Aurélio 1975;

- Lexia: SHORT- origem: inglês. Data: 1975. Dicionário: Aurélio 1975;

- Lexia: TÊNIS - origem: inglês. Data: 1975. Dicionário: Aurélio 1975;

- Lexia: DESIGNER - origem: inglês. Data: 1986. Dicionário: Aurélio 1986;

- Lexia: GRIFE - origem: francês. Data: 1999. Dicionário: Aurélio 1999;

- Lexia: LOOK - origem: inglês. Data: 2001. Dicionário: Houaiss 2001;

- Lexia: TOP - origem: inglês. Data: 2001. Dicionário: Houaiss 2001;

- Lexia: JEANS - origem: inglês. Data: 2001. Dicionário: Houaiss 2001; 
v. 11 (esp.)

81-102 ago. 2021

- Lexia: FASHION - origem: inglês. Data: 2009. Dicionário: Houaiss 2009;

- Lexia: VINTAGE - origem: inglês. Data: 2011. Dicionário: Aulete 2011.

O que se buscou na análise foi estabelecer que tipo de renovação os empréstimos linguísticos e estrangeirismos do corpus trouxeram para o português e, especificamente, para sua variedade brasileira. Dividiram-se os itens linguísticos em três grupos:

Palavras herdadas: aquelas que estão há tanto tempo sendo usadas que a "cidadania estrangeira" delas, como observa Carvalho (2009), passa despercebida aos falantes. São: estampa, joia, moda e modelo;

Novidade semântica: quando a acepção do domínio discursivo da moda foi adicionada posteriormente. Isto quer dizer que as lexias estrangeiras pesquisadas foram legitimadas nos dicionários de português com outras acepções e, mais tarde, as acepções que este estudo buscou foram acrescentadas, ou seja, novos significados foram adicionados a significantes que já existiam na língua. São: ateliê, designer, tênis, top e vintage;

Vocabulário de moda: grupo formado por lexias cujos dados recolhidos nos dicionários do corpus lexicográfico indicam que todas as acepções são relacionadas ao universo da moda ou a acepção primária é deste universo. São: chique, grife, fashion, jeans, lingerie, look, passarela, short e tricô.

Devido a limitações de espaço, neste artigo, foi necessário fazer um recorte para a exposição dos dados e optou-se por apresentar apenas o caso mais relevante de cada um desses três grupos.

\section{Palavras herdadas}

As quatro palavras deste subitem foram inseridas na língua portuguesa há tempo suficiente para passarem por aportuguesamento pleno e não serem mais percebidas como provenientes de outro idioma, como é o caso de moda, um francesismo. Ainda que já seja registrada pelo 
dicionário mais antigo do corpus lexicográfico, o Bluteau (1712- 1728), a primeira informação sobre sua origem foi encontrada no Moraes Silva (1789) que a indicou como vinda do latim modus (informação esta que se repete no Aulete 1881). Mas moda entrou no português através do francês mode, este sim vindo do latim modus, informação que consta nos demais dicionários do corpus lexicográfico que apontaram a origem da lexia simples. Foi o Houaiss 2001 que apresentou um detalhado percurso que validou tal informação, explicando que moda entrou no português no feminino e com a acepção de "costume, estilo momentâneo e não duradouro" (que permanece atrelado à palavra até hoje); a palavra também mantém a classe gramatical do francês: substantivo feminino (no francês há também o substantivo masculino).

Com relação a significados, o primeiro registro, ainda no século XVIII, apresentou a acepção que continua a ser, de modo geral, a primária: "o modo de trajar, falar e fazer qualquer coisa, conforme o costume novamente introduzido". O verbete do Bluteau revelou que, naquele século, a moda ainda era percebida como algo frívolo e um gasto desnecessário (o que, guardadas as devidas proporções, ainda é a opinião de muitos até hoje). Transcreve-se abaixo o verbete 'moda' da obra de Raphael Bluteau'9, (BLUTEAU, 1712-1728, p. 526),

[...] os inventores das modas, não são a gente mais sisuda da Republica, ordinariamente são mulheres \& moços do Norte, incitados por mercadores \& artifices, que não tem outro fim q a propria conveniencia. Esta perpetua variedade de ornatos não deixa de ter perniciosas consequencias, os que a não seguem, parecem ridiculos, os que com ella se conformão, desperdição patrimonios.

A primeira mudança significativa nas acepções para a palavra foi verificada no Aurélio 1975, que apresenta moda como fenômeno social ou cultural, de caráter mais ou menos coercitivo. Mais específico foi o verbete moda no Houaiss 2001,

[...] 1. maneira, gênero, estilo, prevalente (de vestuário, conduta etc.) $<m$. masculina > <entre a elite é $m$. ter um personal trainer $>$ [...] 1.2. freq. conjunto de usos coletivos que caracterizam o vestuário de determinado grupo humano num dado momento $<0$ vermelho está na $m .><$ minissaia está saindo de m.> 1.2.1. abs. a alteração de formas, o uso de novos tecidos, cores, novas matérias-primas etc. surgidos para a indumentária humana por costureiros e figurinistas de renome $\langle a \mathrm{~m}$. outono-inverno $>$ 1.2.2. conjunto das principais tendências ditadas pelos profissionais que trabalham no ramo da moda [...]. (HOUAISS; VILLAR, 2001, p.1940-1941).

9 A transcrição é feita com a ortografia original do verbete. Disponível em: http://dicionarios. bbm.usp.br/pt-br/dicionario/1/moda Acesso: 30/09/2020. 
v. 11 (esp.)

81-102 ago. 2021

Os dados recolhidos revelaram que os verbetes de moda foram recebendo acepções, ao longo do tempo, que se relacionam mais diretamente à indústria do vestuário, como, por exemplo, "arte e técnica do vestuário indústria e/ou comércio dessa arte" (primeiro pelo Aurélio e, mais recentemente, pelo Aulete 2011). Isto é um reflexo de como o setor foi se especializando e um mercado consumidor surgiu; o dicionário geral da língua acaba por refletir essa mudança social e econômica.

O verbete chegou à contemporaneidade refletindo que as práticas da moda (seja em sua face artística, seja em sua face industrial) são aceitas por uma sociedade que a entende como parte integrante da história e da vida cotidiana (não apenas o verbete moda, mas todos os outros desta pesquisa que receberam significados deste setor com o passar dos anos ou foram 'adotados' de outros idiomas, ganhando identidade própria na variedade do português brasileiro ou mantendo suas acepções originais). E, assim, a pesquisa acabou por comprovar que a moda é, ao mesmo tempo, arte (decorativa), indústria, comércio e funciona tanto como símbolo de expressão pessoal quanto de status social.

\section{Novidade semântica}

$\mathrm{O}$ anglicismo vintage se destacou neste grupo por entrar no português com um significado bastante específico da área de enologia e, depois, "receber" um novo, do domínio discursivo da moda, tornandose, assim, um caso de novidade semântica. Empiricamente, notou-se que é com a acepção do domínio discursivo da moda que vintage vem se popularizando e, ao sair de seu domínio discursivo específico e atingir uma parcela considerável da população de falantes, vintage promove uma renovação e ampliação significativa do léxico. Contudo, refletindo a partir da perspectiva lexicográfica, a pesquisa mostrou que a palavra ainda não está tão incorporada ao registro lexicográfico do português brasileiro, visto que só foi encontrada com a acepção desta busca no Aulete 2011 e em um dicionário virtual, o Dicionário InFormal (mas vale observar que o primeiro registro no dicionário virtual é de 2008) ${ }^{10}$.

Nos exemplares analisados no corpus do ELA, vintage teve seu primeiro registro identificado já na edição de 22 de julho de 2000, na página 4. Trata-se de reportagem intitulada "O olho global na

${ }^{10}$ O Dicionário InFormal indica a data de inserção, por parte dos consulentes, do verbete. 
primavera-verão carioca" que aborda as tendências da moda de então. O grifo na palavra vintage é desta pesquisa, visto que o estrangeirismo apareceu sem marcação por parte do semanário.

A malha metálica da Fabricatto brilhou em sutiãs e frentes-
únicas que revivem os dourados e dançantes anos 70. Prepare-
se para vestir o roxo, o lilás, o pink e o cereja em modelos
gênero vintage, que incorporam o broche antigo às peças.
A 'japamania' saiu dos filmes para a roupa nas estampas de
quimono montadas em patchwork, nas gueixas e nos samurais
que ilustram camisetas e segundas-peles.

Retoma-se a suposição já levantada neste artigo de que o redator do texto partiu do princípio de que a maioria de seus leitores, ainda no ano 2000, já conhecia o termo com a acepção do domínio discursivo da moda. A acepção da área de moda remeteu a algo antigo, um "gênero" no sentido de conceito. De acordo com Sabino (2007, p. 628),

a palavra inglesa para designar o ano ou a safra de vinhos e de bebidas foi incorporada ao vocabulário da moda nos anos 80 como referência a roupas de outras épocas. Com o passar do tempo, o vintage estabeleceu-se como uma cultura dentro do universo da moda, gerando, obviamente, novos caminhos de consumo.

Vintage, porém, pertence ao léxico do português há mais tempo com outra acepção. Nesta pesquisa, o verbete foi encontrado pela primeira vez em Houaiss 2001. Lê-se, "vintage [ing.] s.m. ENOL. 1 ano de colheita de um vinho 2. P. tipo de vinho do Porto de qualidade excepcional e proveniente de uma só colheita" (HOUAISS; VILLAR, 2001, p. 2865) e o mesmo dicionário também fornece informações etimológicas, "ETIM. ing. Vintage (sXV) 'id.', do fr. med. vendenge, esse do lat. vindemia, ae 'colheita de uva, vindima'" (HOUAISS; VILLAR, 2001, p. 2865). Diante do verbete do Houaiss 2001, entendeu-se que o anglicismo foi incorporado ao português com a rubrica temática de enologia, sendo um termo específico desta área.

Ao se levar em conta a ideia popularmente difundida de que alguns vinhos ficam melhores com o passar do tempo, observou-se que a acepção da moda, de certa forma, se liga ao sentido primário da palavra vintage. Trata-se de um modo de vestir que resgata peças antigas e de alta qualidade e/ou o estilo de outrora. O Aulete 2011 foi o único dicionário impresso desta pesquisa que, ao registrar a acepção do domínio discursivo da moda em seu verbete apresentou a palavra 


\section{v. 11 (esp.)}

81-102 ago. 2021

como adjetivo para os dois gêneros "( $(a 2 g)$ "11. "Ref. a um produto, uma moda, uma arte etc. que evoca a de um tempo passado, esp. por sua qualidade". (GEIGER, 2011, p. 934).

Quando se pesquisa o verbete nos dicionários virtuais e de acesso livre que compõem o corpus lexicográfico, descobre-se que nem todos a registram. O primeiro a ser pesquisado foi o Aulete digital, que é aproximadamente a versão na internet do impresso Aulete 2011. Há a possibilidade de atualizações no formato digital; os dois, aliás, possuem o mesmo banco de dados. Na proposta do Aulete 2011 (2011, p. vii), a respeito dessa integração, lê-se,

\begin{abstract}
a última versão impressa do Caldas Aulete brasileiro, de 1985, foi adquirida, atualizada, ampliada e reeditada pela Lexikon em formato digital na internet, a partir de 2007, quando o idicionário Aulete passou a ser uma obra aberta, colaborativa e, em consequência, permanentemente atualizada, seja na inclusão de vocábulos novos, seja na ampliação dos registros de novos sentidos, privilegiando-se contextos e usos do português falado no Brasil.
\end{abstract}

Sendo assim, foi bastante curioso, em consulta feita no dia 31/05/2020, notar que o Aulete digital não registrou o verbete vintage, que sua versão impressa apresentou em 2011 (aliás, como apontado anteriormente neste artigo, trata-se do único dicionário impresso do corpus lexicográfico a fazê-lo com a acepção que esta pesquisa busca).

No Dicionário InFormal, a situação foi outra, pois a obra virtual (em consulta realizada no mesmo dia 31/05/2020) apresentou quatro definições para vintage relacionadas a essa busca. A primeira possui registro do dia 18/02/2008 e apresenta uma acepção seguida de um exemplo de uso: "na moda, essa é uma moda retrógrada, uma recuperação de estilos dos anos 20, 30, 40, 50 e 60". A segunda entrada é mais recente, data de 12/11/2014 e define vintage como "algo clássico, de excelente qualidade, se aplica em sapatos vestuário, mobiliário e peças dos anos 1920, 30, 40, 50 e 60", seguido do exemplo de uso: "Gosto do estilo vintage dos anos 60, principalmente no vestuário.". A terceira ${ }^{12}$, com data de 05/09/2008, é retirada da wikipedia (como o final da definição informa) e incorpora as duas acepções da palavra,

vintage é uma designação aplicada a colheitas de uvas, como para o vinho do Porto, em que as condições de produção,

\footnotetext{
${ }^{11}$ Na lista de abreviações usadas no Aulete 2011, "a2g" significa "adjetivo de dois gêneros".

12 Transcrita como no original. Disponível em: https://www.dicionarioinformal.com.br/ vintage/. Acesso: 19/08/2020.
} 
colheita, estágio e outros factores de produção contribuem para uma qualidade excepcional. A sua origem ou significado vem de vint relativo à safra de uvas e age de idade. Denominamse também Vintage os vinhos do porto mais especiais que se caracterizam por ter a capacidade de envelhecer dentro da garrafa, sendo pois um vinho do porto não filtrado que ganha sabores muito especiais com o passar dos anos. O termo vintage foi acolhido pelo mundo da moda para designar peças que marcam uma época, como roupas ou acessórios. [wikipedia]

E a quarta, com data de 19/12/2017, foi incluída por uma usuária de Portugal. Lê-se: "VINT(e)AGE: refere-se a um tempo longo de valorização de um bem/ estado/ [...] pela sua raridade e preservação.".

\section{Vocabulário de moda}

Grife se destacou entre as demais palavras deste grupo por exemplificar uma adoção de um empréstimo sem aparente necessidade de preencher uma lacuna lexical. Em sua acepção, no dicionário Aurélio 1999, o primeiro do corpus lexicográfico a registrá-lo, há a indicação para que o consulente veja o verbete de "assinatura"; o mesmo faz o Houaiss 2001 e, ao término da leitura dos verbetes, concluiu-se que as duas lexias podem ser tomadas como equivalentes. Há ainda no português "marca" que também é um sinônimo.

Grife entrou no léxico já aportuguesada, do original em francês griffe, manteve a mesma classe gramatical (substantivo feminino) e o significado que se atrela à etimologia - da lexia grifa do francês antigo que, de acordo com Houaiss e Villar (2001, p. 1483), no Houaiss 2001, no verbete grife, quer dizer originalmente (1175) "unha pontuda, garra" e ferramentas com este formato. Mais tarde (1798), ganhou o sentido de "instrumento com o qual se imprime uma assinatura" (HOUAISS; VILLAR, 2001, p. 1483) e, posteriormente (1852), passou a ser usada para designar a etiqueta que era costurada dentro da roupa com o nome do estilista que a fazia. Mesmo em seu sentido mais antigo, o de garra, ao se pensar nos ferimentos que um animal deixa em sua presa, a palavra se ligava ao sentido de "marca".

Comprovou-se, com trechos do corpus, que grife, "marca" e "assinatura" podem ser tomados como sinônimos.

No texto Ternurinhas, publicado em 27/10/2007, página 9 do caderno Ela, as três palavras foram usadas. Confirmou-se que "marca" e grife são equivalentes, já assinatura carrega, em seu sentido, a ideia do estilo que o criador imprime, 
v. 11 (esp.)

81-102 ago.

2021 quando a estilista Andrea Marques anunciou que sairia da Maria Bonita Extra, grife em que esteve por 14 anos, deixou nervosa muita gente que gostava de seu trabalho. [...] - Sair da Extra foi uma decisão difícil, muito pensada. Eu entrei lá como estagiária dois anos depois de a marca ter sido criada e aprendi muito com a Cândida (Maria Cândida Sarmento, estilistafundadora da grife), ela me ensinou a apurar o olhar. Tenho o maior orgulho do quanto a marca cresceu. É isso, é como um filho crescido que a gente deixa para o mundo - diz Andrea A mudança é um recomeço para mim, uma experiência para encontrar outro tom, mas a minha assinatura (esses detalhes meigos, a seda e o algodão puros) vou levar sempre.

De qualquer forma, volta-se a considerar a hipótese de que grife não foi adotada por necessidades comunicativas. Ela apresenta, contudo, uma designação especializada e internacional ao vocabulário da moda - e também mais sofisticação. Mas, se irá substituir "marca", é algo que ainda não se pode afirmar.

\section{Considerações finais}

Refletir a respeito da importância do dicionário como obra legitimadora do léxico, em seu formato tradicional - o impresso -, para a sociedade contemporânea é algo necessário diante dos processos comunicativos entre as pessoas, tendo em vista o fato de estarem cada vez mais pautados pela velocidade e pelas exigências imediatistas dos indivíduos que, aparentemente, mostram-se em desacordo com o processo cuidadoso (e, obviamente, demorado) da produção/atualização de um dicionário impresso. Além disso, é inegável que, no mundo contemporâneo, raros são aqueles que vivem sem o apoio constante do conteúdo à disposição no mundo virtual, sobretudo o que é de livre acesso. Os dicionários on-line e gratuitos, além de facilitar e democratizar a consulta a esse tipo de obra, possibilitam ainda a oportunidade de atentar-se para quais diferenças existem em um dicionário que é feito por especialistas (lexicógrafos) e um que é feito por usuários (o que pode provocar certas mudanças em uma obra normativa e legitimadora do léxico, como é o dicionário de língua).

Considerando esses fatos, incluíram-se no corpus lexicográfico três dicionários on-line de acesso gratuito (Aulete digital, Dicionário InFormal e Dicio). O Dicionário InFormal se destacou entre os três por ser o de mais fácil contribuição por parte do usuário-consulente (basta preencher um formulário disponível no site). Trata-se (como a própria página na internet informa) de uma "iniciativa de documentar on- 
line a evolução do português" com a ajuda dos usuários a quem ele convida a definir o seu português (dos usuários). O pronome possessivo "seu" pode ser indicativo de que se trata de um dicionário de usos e, na verdade, se concluiu que é possível afirmar isso do Dicionário InFormal. Isto porque, além dele ser feito pelos consulentes (e numa consequência direta espelhar o vocabulário dos mesmos), é o único do corpus lexicográfico no qual se encontraram verbetes para todos os estrangeirismos buscados, inclusive maison e hype com as acepções do domínio discursivo da moda. Ambas as lexias tiveram significativa frequência no corpus, o que significou que são usadas por um jornal de grande circulação nacional desde o início do século XXI. Sendo assim, mesmo considerando as limitações que o corpus impõe, foi possível se levantar a hipótese de que tais palavras já eram conhecidas por uma parcela de falantes significativa que não são, necessariamente, ligados ao mundo da moda.

O Dicio informou ser composto por mais de 400 mil palavras, mas, ainda assim, não registrou duas das que compõem esta pesquisa: maison e hype. O Aulete digital, por sua vez, em seu site, informou que o banco de dados se compõe de uma parte que vem do dicionário Caldas Aulete da década de 80 e a outra parte de um módulo com 85 mil verbetes que foram atualizados com a colaboração dos usuários. Diante desse cenário, a hipótese inicial era a de que todos os itens lexicais da pesquisa constassem do dicionário digital, mas esta hipótese não se confirmou. O Aulete digital registrou todos os dez empréstimos linguísticos desta busca, com verbetes rigorosamente iguais aos da versão impressa de 2011, porém, com relação aos estrangeirismos, a situação se alterou por causa de uma lexia simples: vintage. Se a versão de 2011 impressa a registrou e com a acepção que se buscou, a versão digital não apresentou o anglicismo. Além disso, os outros três estrangeirismos que não fazem parte da versão impressa - look, maison e hype - tampouco fazem da versão digital e, diante deste resultado, foi difícil identificar, pelo menos no grupo de lexias desta pesquisa, a atualização constante do Aulete digital que a apresentação do site levou a crer.

A principal hipótese levantada foi a de que essas obras virtuais poderiam incorporar mais rapidamente neologismos do que os dicionários gerais da língua portuguesa (devido à facilidade de retirálos de sua nomenclatura, caso as novas palavras não fossem, ao longo do tempo, de fato, incorporadas ao léxico). Além disso, esperava-se que, devido à tecnologia, um dicionário on-line pudesse realizar, de fato, o 


\section{v. 11 (esp.)}

81-102 ago. 2021 conceito de hyperlink que existe no dicionário impresso, mas que não é possível pelas óbvias limitações do papel. Isso tampouco aconteceu, e o máximo da interatividade que essas obras propõem ao usuário é a contribuição. Para além do pouco aproveitamento dos recursos do suporte, fazem falta, nas obras virtuais, informações como proposta lexicográfica detalhada, lista de abreviações e um maior rigor na escolha de abonações e na revisão ortográfica.

Foi o dicionário impresso mais recente do corpus lexicográfico, o Aulete 2011, que registrou quase todos os itens desta busca (reforçando, assim, a necessidade de edições atualizadas desse tipo de obra - o que pareceu ser algo óbvio -, mas a ausência de novas edições impressas ou virtuais de dicionários gerais da língua portuguesa no Brasil demonstrou o contrário). Assim, o que é preciso 'abandonar', ao chegar ao término desta investigação, é a hipótese de que, no Brasil, o que é virtual na área lexicográfica - e aberto à consulta gratuita - é atualizado periodicamente.

Isso revelou uma situação que pode ser classificada, no mínimo, de problemática. Os dicionários impressos não recebem novas edições atualizadas, e o espaço para dicionários gerais da língua na internet existe e já tem alguns ocupantes, mas não é possível que se valorize qualquer dicionário disponível on-line e de acesso livre. Faz-se necessário o reconhecimento da importância desse cenário tecnológico por parte das editoras, universidades e demais instituições governamentais e privadas que atuem no ensino, além da valorização da língua nacional.

Obviamente, ainda mais partindo de um domínio discursivo como o da moda, marcado pelo consumo e pela efemeridade, sabese que dicionários são objetos de consumo e que precisam gerar lucro para suas editoras; além da consciência de que a complementação dos registros lexicográficos é um trabalho infindável. Contudo, o momento para que os dicionários brasileiros da língua portuguesa repensem sua presença nas novas plataformas tecnológicas chegou (e há muito tempo). Caso não se faça nada a respeito, é preciso estar consciente de que vazio este espaço não fica (aliás, não está).

\section{Referências}

ACADEMIA BRASILEIRA DE LETRAS. VOLP: Vocabulário Ortográfico da Língua Portuguesa. São Paulo: Editora Global, 2009. 
ALVES, Ieda Maria. Neologismo: criação lexical. 3. ed. São Paulo: Ática. 2007.

AULETE, Francisco Julio de Caldas. Diccionario contemporaneo da língua portuguesa: feito sobre o plano de F.J Caldas Aulete, Lisboa: Imprensa Nacional, 1881. Disponível em: http://bibdig.biblioteca.unesp.br/handle/10/26034 Acesso em: 08/06/2016.

AZEREDO, José Carlos de. Gramática Houaiss da Língua Portuguesa. 3. ed. São Paulo: Publifolha, 2012.

BASSO, Renato Miguel; GONÇALVES, Rodrigo Tadeu. História concisa da língua portuguesa. Rio de Janeiro: Vozes, 2014.

BIDERMAN, Maria Tereza Camargo. Teoria linguística: linguística quantitativa e computacional. Rio de Janeiro: Livros Técnicos e Científicos, 1978.

BLUTEAU, Raphael. Vocabulario portuguez \& latino: aulico, anatomico, architectonico ... Coimbra: Collegio das Artes da Companhia de Jesus, 1712 1728. 8 v. Disponível em: http://dicionarios.bbm.usp.br/dicionario/edicao/1. Acesso em: 09 jun. 2016.

BORBA, Francisco da Silva. (Org.). Dicionário UNESP do português contemporâneo. São Paulo: Editora UNESP, 2004.

CARVALHO, Nelly. O que é neologismo. São Paulo: Brasiliense, 1987.

CARVALHO, Nelly. Empréstimos linguísticos na língua portuguesa. São Paulo: Cortez, 2009.

CHARAUDEAU, Patrick. Linguagem e discurso: modos de organização. São Paulo: Contexto, 2008.

CORREIA, Margarita; ALMEIDA, Gladis Ma. de Barcellos. Neologia em português. São Paulo: Parábola, 2012.

CUNHA, Antônio Geraldo da. Dicionário etimológico da língua portuguesa. 4. ed. Rio de Janeiro: Lexikon, 2010.

FERREIRA, Aurélio Buarque de Hollanda. Novo dicionário Aurélio da língua portuguesa. 1. ed. Rio de Janeiro: Nova Fronteira, 1975.

FERREIRA, Aurélio Buarque de Hollanda. Novo dicionário Aurélio da língua portuguesa. 2. ed. Rio de Janeiro: Nova Fronteira, 1986.

FERREIRA, Aurélio Buarque de Hollanda. Aurélio século XXI - o dicionário da língua portuguesa. 3. ed. Totalmente rev. e ampl. Rio de Janeiro: Nova Fronteira, 1999.

FERREIRA, Aurélio Buarque de Hollanda. Novo dicionário Aurélio da língua portuguesa. 3. ed. Curitiba: Positivo, 2004.

FERREIRA, Aurélio Buarque de Hollanda. Novo dicionário Aurélio da língua portuguesa. 5. ed. Curitiba: Positivo, 2010.

FREIRE, Laudelino. Grande e novíssimo dicionário da língua portuguesa. 5 
V. 11 (esp.)

81-102 ago. 2021

volumes. 3. ed. Rio de Janeiro: Livraria José Olympio Editora, 1957.

GARCIA, Hamílcar de. Dicionário Contemporâneo da Língua Portuguesa Caldas Aulete. 5 volumes. Rio de Janeiro: Editora Delta, 1958.

GARCIA, Hamílcar de. Dicionário Contemporâneo da Língua Portuguesa Caldas Aulete. 5 volumes. 3. ed. bras. Rio de Janeiro: Editora Delta, 1964.

GARCIA, Hamílcar de. Dicionário Contemporâneo da Língua Portuguesa Caldas Aulete. 5 volumes. 3. ed. bras. Rio de Janeiro: Editora Delta, 1974.

GARCIA, Hamílcar de. Dicionário Contemporâneo da Língua Portuguesa Caldas Aulete. 5 volumes. Rio de Janeiro: Editora Delta, 1980.

GARCIA, Hamílcar de. Dicionário Contemporâneo da Língua Portuguesa Caldas Aulete. 2 volumes. Rio de Janeiro: Editora Delta, 1987.

GEIGER, Paulo. (Org.). Novíssimo aulete - dicionário contemporâneo da língua portuguesa. Rio de Janeiro: Lexikon, 2011.

HOUAISS, Antônio; VILLAR, Mauro de Salles. Dicionário Houaiss da Língua Portuguesa. Rio de Janeiro: Objetiva, 2001.

HOUAISS, Antônio; VILLAR, Mauro de Salles. Dicionário Houaiss da Língua Portuguesa. Rio de Janeiro: Objetiva, 2009.

LEXICAL ANALYSIS SOFTWARE. Wordsmith Tools. Disponível em https:// lexically.net/LexicalAnalysisSoftware/. Acesso em: 10 jun 2017. [software].

MARCUSCHI, Luiz Antônio. Gêneros textuais: definição e funcionalidade. In: DIONÍSIO, Angela Paiva; MACHADO, Anna Rachel; BEZERRA, Maria Auxiliadora. (Orgs.). Gêneros Textuais e Ensino. Rio de Janeiro: Lucerna, 2002.

SABINO, Marco. Dicionário da Moda. Rio de Janeiro: Elsevier, 2007.

OLIVEIRA, Talita Souza de. Moda: um fator social. 2013.125 f. Dissertação. (Mestrado em Ciência Têxtil e Moda) - Universidade de São Paulo, São Paulo, 2013.

SILVA, Antonio Moraes. Diccionario da lingua portugueza - recompilado dos vocabularios impressos ate agora, e nesta segunda edição novamente emendado e muito acrescentado, por ANTONIO DE MORAES SILVA. Lisboa: Typographia Lacerdina,1813. Disponível em: http://www.brasiliana.usp.br/ dicionario/edicao/2 Acesso em: 09 jun.2016. 